\title{
Electroactive microorganisms in bioelectrochemical systems
}

\author{
Bruce E. Logan ${ }^{1 *}$, Ruggero Rossi ${ }^{1}$, Ala'a Ragab $^{2}$ and Pascal E. Saikaly ${ }^{2 *}$ \\ ${ }^{1}$ Department of Civil and Environmental Engineering, The Pennsylvania State University, University Park, PA, USA. \\ ${ }^{2}$ Biological and Environmental Sciences and Engineering Division, Water Desalination and Reuse Research Center, King Abdullah University of Science and Technology, Thuwal, Saudi Arabia \\ *e-mail: blogan@psu.edu; Pascal.Saikaly@kaust.edu.sa
}

Abstract | A vast array of microorganisms from all three domains of life can produce electrical current and transfer electrons to the anodes of different types of bioelectrochemical systems. These exoelectrogens are typically iron-reducing bacteria, such as Geobacter sulfurreducens, that produce high power densities at moderate temperatures. With the right media and growth conditions, many other microorganisms ranging from common yeasts to extremophiles such as hyperthermophilic archaea can also generate high current densities. Electrotrophic microorganisms that grow by using electrons derived from the cathode are less diverse and have no common or prototypical traits, and current densities are usually well below those reported for model exoelectrogens. However, electrotrophic microorganisms can use diverse terminal electron acceptors for cell respiration, including carbon dioxide, enabling a variety of novel cathode-driven reactions. The impressive diversity of electroactive microorganisms and the conditions in which they function provide new opportunities for electrochemical devices, such as microbial fuel cells that generate electricity or microbial electrolysis cells that produce hydrogen or methane.

[H1] Introduction

Microorganisms that can generate an electrical current have been of scientific interest for more than a century ${ }^{1}$, and microorganisms that can directly transfer electrons without added mediators or electron shuttles are the focus of modern bioelectrochemical systems (BOX 1). Such systems are at various stages of development into different technologies that include microbial fuel cells (MFCs) for electricity production, waste water treatment and sensing of toxic chemicals and microbial electrolysis cells (MECs) for electrochemical production of hydrogen or methane gas, as well as other microbial electrochemical technologies (METs) that can be used to desalinate water or produce chemicals such as hydrogen peroxide ${ }^{2,3}$. METs use microorganisms that transfer electrons to a solid electrode (exoelectrogens) or that receive electrons from the electrode (electrotrophs) ${ }^{3}$. Microorganisms transfer electrons to the anode using different methods, including by direct contact of outer membrane cytochromes on the cell surface or on conductive extensions ${ }^{4-6}$, through self-produced mediators such as flavins that can shuttle electrons between the cell and the anode ${ }^{7,8}$ and through conductive pili that can achieve longrange electron transfer. As these mechanisms are summarized in several recent reviews ${ }^{9-12}$, we do not examine them in detail here. In MFCs, spontaneous oxygen reduction at the cathode is the usual means of current generation, typically using platinum or activated carbon as the catalyst, although cobalt, manganese or other materials have been used ${ }^{13}$ (FIG.1). The highest current densities to date come from mixed cultures that are usually dominated by Deltaproteobacteria of the genus Geobacter. However, many other microorganisms can transfer electrons to an anode.

Electrons from the cathode can also fuel abiotic or microbially assisted chemical reactions other than oxygen reduction. Some of these reactions, depending on the specific chemicals and conditions, are spontaneous, whereas others require an additional power source. For example, MECs with a bioanode can spontaneously produce hydrogen if the catholyte has a very acidic $\mathrm{pH}$. A variety of metals can function as favourable electron acceptors to produce spontaneous current, but hydrogen production at neutral or alkaline catholyte $\mathrm{pH}$ values requires additional voltage (FIG. 1). Many different microorganisms, including bacteria and archaea, can grow in pure and mixed cultures using electrons derived from the cathode and different electron acceptors, including nitrate, sulfate and many metals. Perhaps not surprisingly, there is also evidence of direct interspecies electron transfer (DIET) between exoelectrogenic and electrotrophic microorganisms in defined experimental conditions (that is, co-cultures) and in bioreactors such as anaerobic digesters. In this Review, we survey the incredible diversity of electroactive bacterial, archaeal and eukaryotic microorganisms (FIG.2), ranging from model exoelectrogens such as Geobacter sulfurreducens ${ }^{14}$ and Shewanella oneidensis MR-1 (REF. ${ }^{15}$ ) to novel and genetically engineered microorganisms.

[H1] Exoelectrogenic microorganisms

Pure culture experiments have shown that many microorganisms, from all three domains of life, are exoelectrogenic ${ }^{16}$ (FIG. 2a), including bacteria in the Firmicutes and Actinobacteria phyla and in all classes of Proteobacteria, archaea such as the hyperthermophile Pyrococcus furiosus and eukaryotes such as Saccharomyces cerevisiae (FIG. 2a).

The power produced in MFCs is typically not more than a few watts per square metre of projected electrode surface 
area, which is orders of magnitude lower than chemical fuel cells. The amount of power that microorganisms can produce varies widely, with higher power densities sometimes achieved only after long acclimation times in the selective environment of the MFC. Direct comparisons of MFC power densities are possible only when all solution conditions, materials, temperatures, media and reactor conditions (such as electrode spacing) are the same, but that is often not possible given the different growth requirements of cells and the choice of experimental conditions. Even if experimental conditions are identical, power densities can vary owing to electrode age and biofilm development. For example, maximum power densities varied by $15 \%\left(1.36 \pm 0.20 \mathrm{~W} \mathrm{~m}^{-2}\right)$ in 24 studies with similar inocula, electrolytes and materials (waste water inoculum, acetate in $50 \mathrm{mM}$ phosphate buffer, graphite fibre brush anodes and platinum-catalysed cathodes) ${ }^{17}$. For pure cultures of single organisms, no similar comparison of identical but independent studies has been done so far.

Test conditions and reactor configurations vary widely, ranging from simple two-chamber studies with two bottles connected by small tubes (referred to as $\mathrm{H}$ cells) and aerated catholytes to provide oxygen for the reduction reaction to more optimized systems using a ferricyanide catholyte or single-chamber, air cathodes. Ferricyanide is not practical for MFC applications, as it requires energy to regenerate this chemical, but in the laboratory it is useful for growing strictly anaerobic cultures because oxygen can leak through air cathodes into the anolyte and reduce or prohibit power production by certain exoelectrogens ${ }^{18}$. Ferricyanide, however, can inflate power densities compared with those possible using oxygen owing to its more favourable thermodynamic potential.

The area used to normalize power production can also make it difficult to compare power densities between studies. Typically, power is normalized to one of the electrodes, usually the cathode. However, when different-sized electrodes are used, for example, much larger anodes than cathodes, normalizing power to the cathode can exaggerate the power densities compared with equally sized anodes and cathodes ${ }^{19}$. In MFCs with same-sized electrodes, the highest power densities have reached $4,700 \mathrm{~mW} \mathrm{~m}^{-2}$ and $6,400 \mathrm{~mW} \mathrm{~m}^{-2}$ using mixed cultures ${ }^{20,21}$. Large distances between electrodes and the use of membranes can reduce power densities relative to those possible in single-chamber systems with closerspaced electrodes. For example, in typical two-chamber $\mathrm{H}$-type cells that have a membrane in the small tube separating the chambers, high internal resistance limits power. This resistance arises from the low conductivity of the solution, the small cross-sectional areas of the membrane and large distances between the electrodes in the two chambers ${ }^{22}$.

Even with all these differences due to designs and operational conditions, microorganisms can be categorized according to the power densities that are possible in pure cultures: low power production, with $<10 \mathrm{~mW} \mathrm{~m}^{-2}$, suggesting that these microorganisms cannot efficiently perform exogenous electron transfer; $<100 \mathrm{~mW} \mathrm{~m}^{-2}$, although it is uncertain whether current is limited by the ability of the microorganism to transfer electrons or by the reactor architecture; and $>100 \mathrm{~mW} \mathrm{~m}^{-2}$ under optimal reactor conditions and with efficient exoelectrogenic microorganisms, enabling power production in many cases to exceed $>1,000 \mathrm{~mW} \mathrm{~m}^{-2}$ (FIG. 3).

[H2] Exoelectrogenic bacteria. G. sulfurreducens is the most important current-producing bacterium, and it is the most commonly identified exoelectrogenic species in MFCs inoculated with highly diverse and concentrated microbial samples, using media with a near-neutral $\mathrm{pH}$ and fresh water to slightly saline water and moderate temperatures. When the inoculum comes from sediments or waste water and the reactor is fed acetate in a bicarbonate-buffered or phosphate-buffered medium under the above conditions, G. sulfurreducens usually predominates ${ }^{23-25}$. In one study, however, the abundance of Proteiniphilum acetatigenes increased, whereas the abundance of Geobacter spp. decreased with increasing MFC power output, peaking at $6,400 \mathrm{~mW} \mathrm{~m}^{-2}$ (REF. ${ }^{21}$ ). However, P. acetatigenes was not shown to be exoelectrogenic. For complex substrates, such as dairy, domestic, potato and winery waste waters, Geobacter spp. are typically the most abundant known exoelectrogens, although other fermentative bacteria may be more abundant owing to the need to break down the complex organic substrates ${ }^{24,26,27}$. In pure cultures, G. sulfurreducens KN400 (with a ferricyanide catholyte) produced one of the highest known power densities of $3,900 \mathrm{~mW} \mathrm{~m}^{-2}$ (REF. $^{28}$ ). Geobacter spp. produce and transfer electrons through highly conductive pili, enabling efficient transfer of electrons to the anode. Most other exoelectrogenic microorganisms must make direct contact with the anode or produce and release electron shuttles (mediators), which typically do not reach sufficient concentrations to sustain high current densities. Distinguishing G. sulfurreducens from other species is not always possible on the basis of $16 \mathrm{~S}$ rRNA gene sequences. For example, 16S rRNA markers of Geobacter anodireducens and G. sulfurreducens are 100\% identical, but the former can predominate in acetate-fed MFCs owing to its higher tolerance to salinities approaching those of seawater. Notably, G. anodireducens cannot use fumarate as an electron acceptor.

S. oneidensis is another model exoelectrogen ${ }^{15,29-31}$, although it is rarely abundant in MFCs, probably owing to its inability for anaerobic acetate metabolism. Although S. oneidensis MR-1 can produce conductive appendages ${ }^{32}$, these structures are 
extensions of the outer cell membrane ${ }^{32,33}$ rather than pili as in G. sulfurreducens ${ }^{34}$. Shewanella spp. produce mediators and grow primarily as suspended cells or thin biofilms. If mediators are not present in high concentrations, Shewanella spp. can transfer electrons through direct contact of outer membrane cytochromes with a surface ${ }^{4,35}$. If the cells are not on a surface, then frequent contact of suspended cells with the anode is necessary to release the stored electrical charge ${ }^{7,36}$. Therefore, Shewanella spp. usually produce less current than G. sulfurreducens. For example, a direct comparison of S. oneidensis MR-1 and G. sulfurreducens PCA growing on lactate in the same medium and under conditions thought to be optimal for MR-1 showed that current densities were higher for strain PCA than strain MR-1 (REF. ${ }^{37}$ ). Whereas PCA respires acetate and lactate to produce energy, MR-1 relies on substrate-level phosphorylation of lactate ${ }^{38}$. Notably, Shewanella putrefaciens produced $4,400 \mathrm{~mW} \mathrm{~m}^{-2}$ with specially designed electrode materials ${ }^{39}$. In the environment, mediators such as flavins have been detected in marine sediments and pore waters, with the concentrations positively correlated to the concentrations of dissolved manganese, which suggests that the flavins might contribute to the reduction of insoluble manganese through extracellular electron transfer ${ }^{40}$.

Escherichia coli has a legacy as non-exoelectrogen and is often used as a non-exoelectrogenic control ${ }^{18,41}$. However, under special conditions, E. coli can be used to produce current. Certain strains, after extended cultivation or cultivation with chemically treated electrodes, have been reported to produce power densities as high as $3,800 \mathrm{~mW} \mathrm{~m}^{-2}\left(\right.$ (REF. $^{42}$ ), which is comparable to power production by Geobacter or Shewanella strains ${ }^{28,39}$. One omission in E. coli studies, and indeed nearly all pure culture tests, is a lack of proof that the cultures remained pure over time, which is especially a concern when many feeding cycles involve medium replacement, which risks culture contamination. All pure culture results should be verified by tests such as cloning and sequencing of $16 \mathrm{~S}$ rRNA genes to demonstrate a lack of culture contamination, for example, by Geobacter spp.

Many other microorganisms, such as Bacillus subtilis and Klebsiella aerogenes, typically produce quite low current densities in pure cultures (FIG.3). Thus, it has been proposed that such low-power-producing microorganisms are classified as weak exoelectrogens and that production of low current densities is associated with unique roles in biofilm microbial ecology ${ }^{43}$. For example, mediators from Pseudomonas putida help this microorganism to respire using exogenous electron acceptors, but they are toxic to other bacteria and thereby provide a competitive advantage in certain environments ${ }^{44-47}$. Competition in biofilms involves many factors, and the ability to conduct current may not be the only or main reason for the predominance of high-power-producing bacteria. For example, some bacteria in a mixed culture have been found to be capable of higher power production than the mixed culture biofilms they were isolated from that had a greater predominance of other exoelectrogens ${ }^{48}$. Some bacterial strains have shown high power production in long-term cultures, but it is not clear that they can maintain such properties over time. Long-term evolution or repeated culture transfers enabled the development of high-power-producing strains of G. sulfurreducens KN400 (REF. ${ }^{28}$, E. Eoli ${ }^{49}$ and Rhodopseudomonas palustris ${ }^{28}$. In the latter case, the capacity for high power production was lost when the culture was stored and later revived. Exoelectrogenic microorganisms have been found in many extreme environments that have novel methods of electron transfer and other unique properties (BOX 2).

Some results on power production must be viewed with caution owing to medium composition, calculation errors or side reactions. For example, the addition of yeast extract in the medium will introduce mediators such as flavins (for example, riboflavin $)^{50}$, and thus, results with yeast extract do not necessarily indicate the ability of microorganisms to produce current directly with an electrode or self-produced mediators. Several studies included in FIG. 3 used high concentrations of yeast extract $\left(1-5 \mathrm{gl}^{-1}\right)$, which could facilitate power production through mediators. Errors in units have also led to publication of inaccurate current or power densities. For example, one study reported milliamperes instead of microamperes, resulting in current densities exaggerated by three orders of magnitude ${ }^{51}$. Power densities in MFCs that approach or exceed calculated maxima of $15-17 \mathrm{~W} \mathrm{~m}^{-2}$ (based on a first order reaction using microbial kinetics) ${ }^{2,52}$, especially under relatively non-optimal conditions (for example, low conductivity solutions or high internal resistance systems), should be challenged as either an error or a result of non-microbiological reactions. For example, it was claimed that $30 \mathrm{Wm}^{-2}$ could be produced with Enterobacter cloacae $e^{53}$, but this study was later retracted owing to errors ${ }^{54,55}$. Another study reported 40 $\mathrm{W} \mathrm{m}^{-2}$ with a microbial anode $\mathrm{e}^{56}$, but current generation was likely due to copper anode corrosion. Copper is toxic to bacteria, and it can be unsuitable as an anode ${ }^{57}$, although the use of copper remains controversial ${ }^{58}$. A specific reason for a high power density needs to be identified to publish such a finding, or such claims need to be confirmed by independent experiments in other laboratories.

[H2] Exoelectrogenic archaea. Hyperthermophilic archaea can generate electricity at high temperatures, and methanotrophic 
archaea can do the same at moderate temperatures; all these archaea are obligate anaerobes. Power and current densities for archaea have not reached those reported for bacteria. For example, the hyperthermophilic P. furiosus produced 225 $\mathrm{mW} \mathrm{m}^{-2}$ in H-type MFCs with a ferricyanide catholyte at $90{ }^{\circ} \mathrm{C}^{59}$. No yeast extract was used, but resazurin, which is an electron shuttle, was used in the medium, and thus, power production needs to be confirmed in the absence of this chemical. Two other hyperthermophiles known to reduce solid iron and oxidize acetate have produced current densities of $680 \mathrm{~mA} \mathrm{~m}^{-2}$ at $85^{\circ} \mathrm{C}$ (F. placidus) and $570 \mathrm{~mA} \mathrm{~m}^{-2}$ at $80^{\circ} \mathrm{C}$ (Geoglobus ahangari) in MECs using a defined medium and no resazurin ${ }^{60}$. In comparison, G. sulfurreducens PCA produced $1,900 \mathrm{~mA} \mathrm{~m}^{-2}$ in the same reactors ${ }^{60}$. How archaea carry out exogenous electron transfer is unknown.

Methane has been used as a fuel in MFCs but under conditions where microorganisms such as Geobacter spp. were likely responsible for current generation ${ }^{61}$. Mixed cultures generated current in single-chamber MFCs using a medium saturated with methane, and no current was obtained without the methane, but Geobacter spp. and methanogens grew on the anode, and thus both were likely needed for current production ${ }^{61}$. Direct evidence for methanol being an intermediate in power generation from methane was shown in a two-stage process where methane was converted to methanol by methanogens in the first stage, and power was produced in a second-stage MFC likely from methanol oxidation to acetate $^{62}$. Another study genetically engineered the methanogen Methanosarcina acetivorans to produce current in an MFC from methane, but other known exoelectrogens identified in the biofilm were thought to be responsible for current generation ${ }^{63}$.

[H2] Exoelectrogenic eukaryotes. Fungi can also generate electricity, specifically members of the order Saccharomycetaceae, such as S. cerevisiae (brewer's or baker's yeast). Yeast-based MFCs typically reach 20-70 $\mathrm{mW} \mathrm{m}^{-2}$ in the absence of

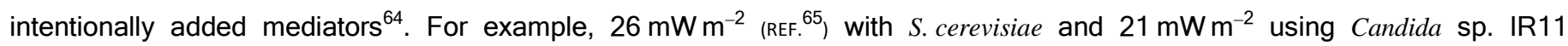
(REF. ${ }^{66}$ ). Generating higher power is possible using optimized materials, for example, Candida melibiosica produced $720 \mathrm{~mW} \mathrm{~m}^{-2}$ with a nickel nanostructured carbon felt anode and a ferricyanide catholyte ${ }^{67}$. Anode modification with mediators and immobilized S. cerevisiae cells enabled $2,440 \mathrm{~mW} \mathrm{~m}^{-2}$ (REF. ${ }^{64}$ ). Most (but not all) MFC studies with Saccharomycetaceae have used yeast extract, which as previously noted can introduce mediators ${ }^{68}$. However, yeast extract does not necessarily increase power. In one study, current doubled when yeast cells were subsequently grown in a medium lacking yeast extract (containing only carbohydrates in an acetate buffer) ${ }^{64}$. Electron transfer through endogenous mediators secreted into solution has been shown for few species (Blastobotrys adeninivorans, C. melibiosica and Pichia stipites) ${ }^{64,69}$, but there is also evidence for direct electron transfer from the cell surface ${ }^{64}$. Progress in using yeast in MFCs may be limited by the more complex and compartmentalized structure of eukaryotic cells compared with bacteria and archaea and a lack of knowledge about the specific components of the yeast cell membrane that could be involved in exogenous electron transfer. Future studies using yeasts as biocatalysts should elucidate the electron transfer process and demonstrate current generation in the absence of yeast extract.

[H1] Electrotrophic microorganisms

[H2] Bacterial biocathodes. Bacterial biofilms have long been known to facilitate oxygen reduction on metals ${ }^{70}$, and in a seawater fuel cell biofilms on a carbon cathode improved power generation using a sacrificial magnesium alloy anode ${ }^{71}$. Electrotrophic activity by pure cultures in a bioelectrochemical cell was first reported for Geobacter metallireducens, which converted nitrate to nitrite ${ }^{72}$, and later for the betaproteobacteria Alcaligenes faecalis. Many studies have shown nitrate

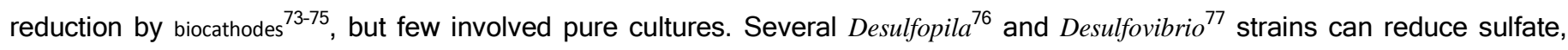
and Desulfovibrio paquesii can produce $\mathrm{H}_{2}$ gas but only at highly negative potentials ( $-900 \mathrm{mV}$ versus a standard hydrogen electrode or lower) ${ }^{78}$.

One of the first pure culture studies that showed electrotrophic oxygen reduction used Klebsiella pneumoniae, which reduced manganese oxides deposited on the cathode ${ }^{79}$ and increased oxygen reduction on stainless steel electrodes ${ }^{80}$. Several bacteria were isolated from electroactive cathodic biofilms that produce modest currents in seawater: most often Proteobacteria (Acinetobacter johnsonii, Pseudoalteromonas spp., Marinobacter spp., Gammaproteobacteria, Roseobacter spp. and Alphaproteobacteria ${ }^{81,82}$ ) but also Bacteroidetes (Winogradskyella poriferorum ${ }^{81}$ ) and Firmicutes (Bacillus spp. $^{81}$ ). Some bacteria that show high levels of oxygen reduction in biocathodes can be identified through metagenomic analysis but so far have not been grown in pure cultures, such as Candidatus Tenderia electrophaga ${ }^{83}$.

Biocathodes can reduce many different metals, offering a potential route to recover metals from waste water ${ }^{84}$. Some of the bacteria used for this purpose are model exoelectrogens. For example, G. sulfurreducens and S. oneidensis can reduce 
and precipitate particles of pure palladium ${ }^{85}$. Other bacteria oxidize iron, such as the chemolithotrophic bacterium Acidithiobacillus ferrooxidans ${ }^{86}$. Biofilms that generate hydrogen on a cathode under anoxic conditions ${ }^{87}$ could be very useful for all biocathodes if the hydrogen then fuels reduction of other electron acceptors, including nitrate, sulfate, metals and carbon dioxide. G. sulfurreducens PCA increased hydrogen production from a cathode ${ }^{88}$, but this strain is not autotrophic, and therefore its growth on the cathode cannot be sustained without an organic substrate. Hydrogen-producing biofilms predominantly contain Desulfovibrio spp. $^{78}$.

Biocathodes that use electricity to reduce carbon dioxide to multi-carbon organic molecules, in a process termed microbial electrosynthesis, are of great interest for the production of industrial feedstocks and biofuels ${ }^{89,90}$. Initial studies demonstrated that acetogenic bacteria, such as Sporomusa spp. and Clostridium spp., can accept electrons from cathodes and reduce carbon dioxide to acetate ${ }^{91,92}$. Subsequently, several other strains were shown to produce acetate from electrical current $^{93-95}$ (FIG. 4). However, the current densities were all relatively low (typically $<10 \mathrm{~mA} \mathrm{~m}^{-2}$ ), and the cathodic coulombic efficiencies (that is, consumed electrons present in products) were highly variable (34-91\%). Mediators may have had a role in current generation in some of these studies, as five of the seven studies that reported current densities $>100$ $\mathrm{mA} \mathrm{m}^{-2}$ used yeast extract. Furthermore, several studies used potentials more negative than were needed to produce hydrogen gas under standard conditions $(-0.414 \mathrm{~V})$. However, hydrogen production can occur at more positive potentials if the bulk phase hydrogen concentration is kept low (for example, at $-0.330 \mathrm{~V}$ for $<10^{-3} \mathrm{~atm}$ at $\mathrm{pH} 7$ ) $^{96}$. Thus, the role of direct electron transfer versus acetogenesis of hydrogen gas cannot be well separated in many of these studies.

[H2] Archaea on the cathode. Hydrogen-producing MECs with mixed cultures that contain archaea inevitably also produce methane ${ }^{97}$. Pure cultures of methanogens on a cathode can produce methane, but rates are usually low (2.3-44 mmol day $\left.{ }^{-1} \mathrm{~m}^{-2}\right)^{98}$, with current densities $<500 \mathrm{mAm}^{-2}$ (FIG.4). With mixed cultures, rates have increased to 1,200 mmol day ${ }^{-1} \mathrm{~m}^{-2}$, with current densities $>10 \mathrm{~A} \mathrm{~m}^{-2} \mathrm{~A} \mathrm{~m}^{2}$ (REF. ${ }^{99}$ ). The mechanisms used by methanogens to convert this current into methane are debated. Direct conversion of current into methane, referred to as electromethanogenesis, was initially postulated for a mixed culture dominated by Methanobacterium spp. on the basis of much higher methane production rates than those possible using $\mathrm{H}_{2}$ generated by abiotic cathodes and the lack of another plausible explanation ${ }^{100}$. As a biocathode with a hydrogenase-deficient mutant of Methanococcus maripaludis MM901 produced methane, an involvement of cell-associated hydrogenases was discounted ${ }^{11}$. However, the rate of methane production was only $10 \%$ of that produced by the parent strain. It was subsequently shown that cell-free suspensions of spent media of M. maripaludis cultures produced formate or $\mathrm{H}_{2}$ gas at rates sufficient to explain methane production in tests with the cells present ${ }^{101}$. Thus, it was concluded that direct electron transfer for this species was not needed to account for observed rates of methane production. However, most studies have shown a clear predominance of Methanobacterium spp. on the cathode ${ }^{102}$ and most often Methanobacterium palustre using cathode materials that are poor catalysts for hydrogen evolution ${ }^{100,103}$. Consequently, findings with M. maripaludis cannot necessarily be extended to explain methane production in MECs by Methanobacterium spp. With cathodes containing catalysts that readily support abiotic hydrogen production such as platinum, different methanogens dominate such as Methanobrevibacter spp. ${ }^{103}$, suggesting that the mechanism of methane production is different when hydrogen gas readily arises than when methane is produced from poorly catalysed electrodes.

[H1] Microbial electroecology

The ecology of electroactive microorganisms in biofilms is a relatively new and vital area of research. Natural systems are built around cycles, so it is not surprising that electroecological cycles could exist that are sustained by direct electron transfer between microorganisms or indirect exchange using naturally occurring (or engineered) conductive materials. Such exchanges of electrons are explored in controlled studies with specific microorganisms, but there is accumulating evidence that microorganisms have complex symbiotic (or even parasitic) interactions on the basis of electron exchange by direct cell-cell contact, longer-range conductive microbial appendages or pili or using electrically conductive abiotic materials.

[H2] Direct interspecies electron transfer. The direct transfer of electrons from exoelectrogens to other microorganisms that occurs between the same species or genera or between completely different phyla is collectively referred to as DIET. Electron transfer between two different microorganisms was first shown in a co-culture, in which G. metallireducens transferred electrons derived from ethanol oxidation to G. sulfurreducens ${ }^{104}$ (FIG.5a). Bacteria and archaea can also exchange electrons with each other, as shown in a co-culture of G. metallireducens and Methanosarcina barkeri or Methanosaeta harundinacea ${ }^{105,106 .}$ Methanosarcina spp. are diverse methanogens that can oxidize hydrogen, acetate and single-carbon compounds such as methanol. Interestingly, M. harundinacea is acetoclastic, which suggests that the mechanisms of DIET involving this archaeon 
are different than those for methane production from cathodes, which primarily contain Methanobacterium spp.

Another recent area of great interest is increased rates of methane production or ethanol consumption in response to the addition of conductive particles to cell suspensions or to anaerobic digesters. In this setting, electron transfer likely occurs between two microorganisms that are not in direct contact (and not connected by conductive pili); instead, the cells use a conductive surface to facilitate transfer of electrons (FIG.5b). For example, adding very small conductive particles (magnetite and semi-conductive haematite) improved rates of methane production by methanogenic communities, but nonconductive ferrihydrite did not ${ }^{107}$. Magnetite can effectively replace $c$-type cytochromes for electron transfer between G. metallireducens and G. sulfurreducens ${ }^{108}$, and ferrihydrite improved methane production in co-cultures of G. metallireducens and M. barkeri $^{105}$. Furthermore, conductive granular activated carbon (GAC) particles also increased electron transfer between G. metallireducens and M. barkeri ${ }^{105}$ (FIG. 5c). Numerous reports showed that GAC can improve the performance of anaerobic digesters. However, the relative importance of different factors that can increase methane production when particles are added, such as greater particle surface area that can increase the concentration of microorganisms in the system, chemical adsorption (either substrates or inhibitory chemicals) onto very adsorptive surfaces such as GAC or the presence of metals that can function as electron shuttles, has not been well separated from DIET in many studies ${ }^{109}$.

[H2] Cooperative power generation. Microorganisms can cooperate synergistically to increase power production, and this synergism can be exploited in applications. In co-cultures with exoelectrogenic microorganisms, other bacteria can facilitate current generation by removal of chemicals or production of a substrate for current generation. For example, in co-culture with G. sulfurreducens, E. coli removed oxygen and thus maintained anaerobic conditions ${ }^{18,110}$. Another cooperative method of growth was observed for Acetobacteraceti and Gluconobacter roseus. Although both species individually can generate power from substrate oxidation owing to their periplasmic quinoheme protein-cytochrome $c$ complexes and membrane-bound ubiquinone, co-cultures achieved higher rates of substrate removal and a greater maximum power density $\left(140 \mathrm{~mW} \mathrm{~m}^{-3}\right)$ than the individual strains ${ }^{111}$. Often, exoelectrogens can use breakdown products by other cells to generate current. For example, Ruminiclostridium cellulolyticum fermented cellulose, and these fermentation products fuelled current production by G. sulfurreducens ${ }^{112}$. Mutually beneficial cooperation between fermenters and exoelectrogens also improves power output, as demonstrated in the combination of K. aerogenes and Pseudomonas aeruginosa PA14. K. aerogenes fermented glucose to 2,3-butanediol, which P.aeruginosa consumed, leading to increased phenazine production in P. aeruginosa, which consequently shifted the $K$.aerogenes metabolism from fermentation towards electrode-based respiration, further increasing the current production $^{113}$. There are many examples of such beneficial relationships between exoelectrogens and other microorganisms and more likely to be identified in the future, especially when the growth medium contains complex mixtures of organic matter.

[H2] Interactions of microorganisms that release electrons by different mechanisms. An important feature of Geobacter spp. is their ability to form relatively thick and highly conductive biofilms on electrodes, which can enable high current densities ${ }^{114,115}$. Many other microorganisms do not produce these thick biofilms owing to an inability to produce pili that can conduct electrons over long distances. However, we lack information on how other microorganisms interact with these conductive pili in mixed species biofilms, which could aid in understanding the increased power densities by these mixed cultures compared with pure cultures of Geobacter spp. Other microorganisms also have the ability to form conductive pili, as shown recently when pilin genes from Flexistipes sinusarabici, Calditerrivibrio nitroreducens or Desulfurivibrio alkaliphilus were expressed in G. sulfurreducens instead of its native pilin gene ${ }^{116}$. Unravelling the importance and functions of these microorganisms that harbour conductive pili and their interactions with microorganisms that must make direct contact with a conductive surface (or produce mediators) will be important for understanding the functional electroecology of microorganisms in bioelectrochemical systems.

[H1] Genetic engineering and synthetic biology

Synthetic biology is being explored to increase performance of known exoelectrogens and to greatly improve current production by microorganisms with little measurable current production in bioelectrochemical systems. Several genetic engineering studies focused on the model exoelectrogen S. oneidensis to improve its substrate range and overall electron flux. Adding genes that encode metabolic pathways from other microorganisms, including E. coli, Zymomonas mobilis, Candida intermedia and Clostridium acetobutylicum, has expanded the substrate range of different S. oneidensis strains from 2- and 3carbon molecules to 5- and 6-carbon molecules, such as $x$ lose ${ }^{117}$, glucose ${ }^{118}$ and glycerol ${ }^{119}$. The addition of a light-driven proton pump from a marine bacterium increased the proton motive force of S. oneidensis and consequently its substrate 
uptake rate, resulting in a $250 \%$ increase in current production ${ }^{120}$. Better overall biofilm conductivity can improve current production by lowering charge-transfer resistance at the biofilm-electrode interface; for example, G. sulfurreducens strain CL-1 with a gene deleted to form more cohesive biofilms produced $70 \%$ higher power densities than the wild-type strain $^{121}$. Modifying genes to improve biofilm formation also increased power production by S. oneidensis ${ }^{122,123}$. As mentioned above, G. sulfurreducens PCA is not capable of autotrophic growth; however, strain ACL was engineered to contain an ATPdependent citrate lyase, enabling it to use carbon dioxide to generate biosynthetic precursors through the reverse tricarboxylic acid cycle. The engineered strain consumed ten times as much current as the wild-type strain $\left(\geq 800 \mathrm{~mA} \mathrm{~m}^{-2}\right)$ when grown on a cathode ${ }^{124}$. Increased electron flux is also possible by genetically altering electron shuttle mechanisms. Adding the B. subtilis riboflavin synthesis pathway in S. oneidensis led to a 25 -fold increase in flavin production and consequently 15-fold higher current densities than those seen in the wild-type strain ${ }^{125}$. In another example, CRISPR technology was used to manipulate extracellular electron transport in S. oneidensis MR-1 at both the transcriptional and translational level; specifically, CRISPR interference (CRISPRi) and an Hfq-dependent small regulatory RNA (sRNA) controlled current generation by repressing $c$-type cytochrome $m t r A B C$ pathway genes and the biofilm formation genes speF and $u v r Y^{126}$. Whereas the MtrABC pathway is crucial for electron transport, SpeF and UvrY negatively affect biofilm formation and thus current generation. A combined CRISPRi-SRNA system led to stronger repression than the individual systems. Overall, these systems could increase (up to 1.7-fold) or decrease (up to 8.7-fold) power generation in S. oneidensis MR-1, depending on the targeted gene. Developing these kinds of regulatory tool is important to efficiently control EET and power output in known exoelectrogens and to elucidate EET pathways in new or less understood exoelectrogens by allowing for simultaneous multi-gene control and a spectrum of gene repression that is not achievable by knockout techniques.

Bacteria such as E. coli can also be engineered to produce much higher currents than the low levels of the wild-type strains by introducing certain pathways from known exoelectrogens, for example, the Mtr pathway from S. oneidensis MR-1 (REF. ${ }^{27}$ ). A synthetic cymA-mtr pathway enabled complete lactate oxidation in E.coli, achieving a fourfold increase in current generation to $\sim 160 \mathrm{mAm}^{-2}$, with no adverse effects on bacterial survival and anode attachment. Another E. coli strain was modified with a phenazine-1-carboxylic acid synthesis pathway from P. aeruginosa, which functioned as an electron shuttle and thus increased current production as well ${ }^{128}$.

Synthetic engineering can also be used to improve cooperation between different microorganisms. In one example of engineered cooperation, B. subtilis strain $\mathrm{RH} 33$ was modified to produce multiple copies of the riboflavin operon ${ }^{129}$, resulting in the accumulation of up to $12 \mathrm{~g} \mathrm{l}^{-1}$ riboflavin, which was used as an electron shuttle by S. oneidensis MR-1 for improved current production. This cooperative pair achieved a maximum anodic power density of $277 \mathrm{~mW} \mathrm{~m}^{-2}$, which is substantially higher than the powers achieved by either pure culture. In another example, E. coli and B. subtilis were engineered to ferment glucose to lactate as a carbon source and riboflavin as an electron shuttle for increased current generation by S. oneidensis ${ }^{130}$. To complete this 'cross-feeding' mutualism, S. oneidensis oxidized lactate to acetate as a carbon source for the two fermenters. This designed cooperation allowed for current generation from glucose, which S. oneidensis cannot utilize as a carbon source, and increased electron transfer and power output. Synthetic biology can also enable a microorganism to use new substrates or to produce chemicals that can be used for current generation by exoelectrogens. For example, a $M$. acetivorans strain, engineered to express methyl-coenzyme $M$ reductase (derived from anaerobic methylotrophs), converted methane into acetate, which then fuelled current generation by G. sulfurreducens $^{63}$. In a methane-acclimated sludge that included Paracoccus denitrificans, a microorganism that produces electron shuttles, this synthetic consortium achieved a power density of $168 \pm 9 \mathrm{~mW} \mathrm{~m}^{-2}$.

[H1] Outlook

The ability of microorganisms to generate electrical current or to accept and use electrons continues to be a fascinating and rapidly developing field. One barrier to identifying new electroactive microorganisms is a lack of methods to accurately screen if a species is electrochemically active. Phylogenetically, electroactive microorganisms are highly diverse, which makes it difficult to develop small subunit ribosomal RNA-base molecular biology tools to identify them. Also, no conserved functional gene exists, unlike $p p k l$, which is a marker for phosphorous-accumulating organisms, or amoA in ammoniaoxidizing bacteria, so no PCR primers or fluorescence in situ hybridization (FISH) probes are available to specifically target electrochemically active microorganisms. However, new microorganisms with extracellular electroactivity continue to be discovered, and the mechanisms of electron transfer have expanded with the discovery of cable bacteria that can transfer electrons along the length of filaments to electrically join anoxic and aerobic environments in sediments. Interactions of microorganisms through direct contact, conductive pili or particles open up a wide range of possible ecological relationships 
within biofilms, which were once thought to be limited by diffusion of simple inorganic and organic molecules. Monitoring the exchange of electrons, however, is much more challenging than that of molecules, as current transport between microorganisms cannot be directly measured. The bioelectroecology of biofilms and the development of microbial communities on the basis of electron transfer are relatively new areas for exploration of how microorganisms can communicate, grow and develop. Technologies based on electroactive microorganisms are still in a nascent stage, but as advances in materials development and our scientific discoveries of methods of electron transfer continue, it can be anticipated that existing MFC and MEC technologies can be further refined and that new applications, for example, as sensors or as interfaces with bioelectronic devices, will be found to exploit the unusual capabilities of these extraordinary electroactive microorganisms.

1. Potter, M. C. Electrical effects accompanying the decomposition of organic compounds. Proc. R. Soc. Lond. B Biol. Sci. 84, 260-276 (1911).

2. Logan, B. E. Microbial Fuel Cells (John Wiley \& Sons, Inc., 2008).

Logan, B. E. \& Rabaey, K. Conversion of wastes into bioelectricity and chemicals using microbial electrochemical technologies. Science 337, 686-690 (2012).

Myers, J. M. \& Myers, C. R. Role for outer membrane cytochromes OmcA and OmcB of Shewanella putrefaciens MR-1 in reduction of manganese dioxide. Appl. Environ. Microbiol. 67, 260-269 (2001).

El-Naggar, M. Y. et al. Electrical transport along bacterial nanowires from Shewanella oneidensis MR-1. Proc. Nat. Acad. Sci. USA 107, 18127-18131 (2010).

Pirbadian, S. et al. Shewanella oneidensis MR-1 nanowires are outer membrane and periplasmic extensions of the extracellular electron transport components. Proc. Nat. Acad. Sci. 111, 12883-12888 (2014).

von Canstein, H., Ogawa, J., Shimizu, S. \& Lloyd, J. R. Secretion of flavins by Shewanella species and their role in extracellular electron transfer. Appl. Environ. Microbiol. 74, 615-623 (2008).

Xu, S., Jangir, Y. \& El-Naggar, M. Y. Disentangling the roles of free and cytochrome-bound flavins in extracellular electron transport from Shewanella oneidensis MR-1. Electrochim. Acta 198, 49-55 (2016).

Lovley, D. R. Syntrophy goes electric: direct interspecies electron transfer. Ann. Rev. Microbiol. 71, 643-664 (2017).

10. Lovley, D. R. Happy together: microbial communities that hook up to swap electrons. ISME J. 11, 327-336 (2017).

11. Light, S. H. et al. A flavin-based extracellular electron transfer mechanism in diverse Gram-positive bacteria. Nature 562, 140-144 (2018).

12. Reguera, G. Harnessing the power of microbial nanowires. Microb. Biotechnol. 11, 979-994 (2018).

13. Wang, Z., Cao, C., Zheng, Y., Chen, S. \& Zhao, F. Abiotic oxygen reduction reaction catalysts used in microbial fuel cells. ChemElectroChem 1, 1813-1821 (2014).

14. Bond, D. R. \& Lovley, D. R. Electricity production by Geobacter sulfurreducens attached to electrodes. Appl. Environ. Microbiol. 69, 1548-1555 (2003).

15. Bretschger, O. et al. Current production and metal oxide reduction by Shewanella oneidensis MR-1 wild type and mutants. Appl. Environ. Microbiol. 73, 7003-7012 (2007).

16. Koch, C. \& Harnisch, F. Is there a specific ecological niche for electroactive microorganisms? ChemElectroChem 3, 1282-1295 (2016).

17. Yang, W., Kim, K.-Y., Saikaly, P. E. \& Logan, B. E. The impact of new cathode materials relative to baseline performance of microbial fuel cells all with the same architecture and solution chemistry. Energy Environ. Sci. 10, 1025-1033 (2017).

18. Qu, Y., Feng, Y., Wang, X. \& Logan, B. E. Use of a coculture to enable current production by Geobacter sulfurreducens. Appl. Environ. Microbiol. 78, 3484-3487 (2012)

19. Oh, S. \& Logan, B. E. Proton exchange membrane and electrode surface areas as factors that affect power generation in microbial fuel cells. Appl. Microbiol. Biotechnol. 70, 162-169 (2006). This paper addresses how power densities can vary depending on relative electrode sizes and the membrane cross-sectional area in two-chamber MFCs.

20. Yang, W. \& Logan, B. E. Immobilization of a metal-nitrogen-carbon catalyst on activated carbon with enhanced cathode performance in microbial fuel cells. ChemSusChem 9, 2226-2232 (2016). This paper demonstrates high power densities using activated carbon air cathodes.

21. Oliot, M. et al. Separator electrode assembly (SEA) with 3-dimensional bioanode and removable air-cathode boosts microbial fuel cell performance. J. Power Sources 356, 389-399 (2017). This paper demonstrates the highest power density for electrodes with equal projected surface area.

22. Liang, P., Huang, X., Fan, M.-Z., Cao, X.-X. \& Wang, C. Composition and distribution of internal resistance in three types of microbial fuel cells. Appl. Microbiol. Biotechnol. 77, 551-558 (2007).

23. Holmes, D. E. et al. Microbial communities associated with electrodes harvesting electricity from a variety of aquatic sediments. Microb. Ecol. 48, 178-190 (2004). This is an analysis of the communities in a variety of sediments from natural system.

24. Kiely, P. D., Regan, J. M. \& Logan, B. E. The electric picnic: synergistic requirements for exoelectrogenic microbial communities. Curr. Opin. Biotechnol. 22, 378-385 (2011).

25. Lovley, D. R. Bug juice: harvesting electricity with microorganisms. Nat. Rev. Microbiol. 4, 497-508 (2006).

26. Kiely, P. D., Rader, G., Regan, J. M. \& Logan, B. E. Long-term cathode performance and the microbial communities that develop in microbial fuel cells fed different fermentation endproducts. Bioresour. Technol. 102, 361-366 (2011).

27. Kiely, P. D. et al. Anode microbial communities produced by changing from microbial fuel cell to microbial electrolysis cell operation using two different wastewaters. Bioresour. Technol. 102, 388-394 (2011).

28. $\mathrm{Yi}, \mathrm{H}$. et al. Selection of a variant of Geobacter sulfurreducens with enhanced capacity for current production in microbial fuel cells. Biosens. Bioelectron. 24, 3498-3503 (2009).

28. $\mathrm{Yi}, \mathrm{H}$. et al. Selection of a variant of Geobacter sulfurreducens with enhanced capacity for current production in microbial fuel cells. Biosens. Bioelectron. 24, 3498-
29. Ringeisen, B. R. et al. High power density from a miniature microbial fuel cell using Shewanella oneidensis DSP10. Environ. Sci. Technol. 40, 2629-2634 (2006).

30. Rosenbaum, M., Cotta, M. A. \& Angenent, L. T. Aerated Shewanella oneidensis in continuously fed bioelectrochemical systems for power and hydrogen production. Biotechnol. Bioeng. 105, 880-888 (2009).

31. Watson, V. J. \& Logan, B. E. Power production in MFCs inoculated with Shewanella oneidensis MR-1 or mixed cultures. Biotechnol. Bioeng. 105, 489-498 (2010).

32. Gorby, Y. A. et al. Electrically conductive bacterial nanowires produced by Shewanella oneidensis strain MR-1 and other microorganisms. Proc. Natl Acad. Sci. USA 103, 11358-11363 (2006). This is the first published report on conductive appendages of the Shewanella genus.

33. Subramanian, P., Pirbadian, S., El-Naggar, M. Y. \& Jensen, G. J. Ultrastructure of Shewanella oneidensis MR-1 nanowires revealed by electron cryotomography. Proc. Natl Acad. Sci. USA 115, E3246-E3255 (2018). This paper provides a clear description of the appendages produced by Shewanella oneidensis MR-1.

34. Reguera, G. et al. Extracellular electron transfer via microbial nanowires. Nature 435, 1098-1101 (2005).

This is the first description of conductive pili produced by Geobacter sp.

35. Myers, C. R. \& Myers, J. M. Localization of cytochromes to the outer membrane of anaerobically grown Shewanella putrefaciens MR-1. J. Bacteriol. 174, 3429-3438 (1992).

36. Marsili, E. et al. Shewanella secretes flavins that mediate extracellular electron transfer. Proc. Natl Acad. Sci. USA 105, 3968-3973 (2008).

37. Call, D. F. \& Logan, B. E. Lactate oxidation coupled to iron or electrode reduction by Geobacter sulfurreducens PCA. Appl. Environ. Microbiol. 77, 8791-8794 (2011). This paper provides a direct comparison of current production of $G$. sulfurreducens and $S$. oneidensis using the same substrate.

38. Hunt, K. A., Flynn, J. M., Naranjo, B. n., Shikhare, I. D. \& Gralnick, J. A. Substrate-Level phosphorylation is the primary source of energy conservation during anaerobic respiration of Shewanella oneidensis strain MR-1. J. Bacteriol. 192, 3345-3351 (2010).

This paper provides a clear explanation of the basis for current generation by a Shewanella species.

39. Yang, L. et al. Boosting current generation in microbial fuel cells by an order of magnitude by coating an ionic liquid polymer on carbon anodes. Biosens. Bioelectron. 91, 644-649 (2017).

40. Monteverde, D. R. et al. Distribution of extracellular flavins in a coastal marine basin and their relationship to redox gradients and microbial community members. Environ. Sci. Technol. 52, 12265-12274 (2018).

41. Cao, X., Huang, X., Zhang, X., Liang, P. \& Fan, M. A mini-microbial fuel cell for voltage testing of exoelectrogenic bacteria. Front. Environ. Sci. Eng. 3, 307-312 (2009).

42. Li, H. et al. Power output of microbial fuel cell emphasizing interaction of anodic binder with bacteria. J. Power Sources 379, 115-122 (2018).

43. Doyle, L. E. \& Marsili, E. Weak electricigens: a new avenue for bioelectrochemical research. Bioresour. Technol. 258, 354-364 (2018).

44. Rabaey, K., Lissens, G., Siciliano, S. D. \& Verstraete, W. A microbial fuel cell capable of converting glucose to electricity at high rate and efficiency. Biotechnol. Lett. 25, 1531-1535 (2003).

45. Rabaey, K., Boon, N., Siciliano, S. D., Verhaege, M. \& Verstraete, W. Biofuel cells select for microbial consortia that self-mediate electron transfer. Appl. Environ. Microbiol. 70, $5373-5382$ (2004).

46. Rabaey, K., Boon, N., Hofte, M. \& Verstraete, W. Microbial phenazine production enhances electron transfer in biofuel cells. Environ. Sci. Technol. 39, 3401-3408 (2005)

This paper demonstrates the role of phenazines for mediating electron transfer.

47. Pham, T. H. et al. Metabolites produced by Pseudomonas sp. enable a Gram positive bacterium to achieve extracellular electron transfer. Appl. Microbiol. Biotechnol. 77 , 1119-1129 (2008).

48. Kiely, P. D., Call, D. F., Yates, M. D., Regan, J. R. \& Logan, B. E. Anodic biofilms in microbial fuel cells harbor low numbers of higher-power producing bacteria than abundant genera. Appl. Microbiol. Biotechnol. 88 $371-380(2010)$.

49. Zhang, T. et al. A novel mediatorless microbial fuel cell based on biocatalysis of Escherichia coli. Chem. Commun. (Camb.) 21, 2257-2259 (2006).

50. Sayed, E. T., Saito, Y., Tsujiguchi, T. \& Nakagawa, N. Catalytic activity of yeast extract in biofuel cell. J. Biosci. Bioeng. 114, 521-525 (2012).

51. Holmes, D. E., Nicoll, J. S., Bond, D. R. \& Lovley, D. R. Potential role of a novel psychrotolerant member of the family Geobacteraceae, Geopsychrobacter electrodiphilus gen. nov., sp. nov., in electricity production by a marine sediment fuel cell. Appl. Environ. Microbiol. 70, 6023-6030 (2004); erratum 75, 885 (2009).

52. Logan, B. E. Exoelectrogenic bacteria that power microbial fuel cells. Nat. Rev. Microbiol 7, 375-381 (2009).

53. Samrot, A. V. et al. Electricity generation by Enterobacter cloacae SU-1 in mediator less microbial fuel cell. Int. J. Hydrogen Energy 35, $7723-7729$ (2010).

54. Angenent, L. et al. Comments on “Electricity generation by Enterobacter cloacae SU-1 in mediator less microbial fuel cell” by Samrot et al., Int. J. Hydrogen Energy, 35 (15) 2010, $7723-7729$. Int. J. Hydrogen Angenent, L. et al. Comments
Energy 36, 9396-9397 (2011).

55. Samrot, A. V. et al. Retraction notice to: Electricity generation by Enterobacter cloacae SU-1 in mediator less microbial fuel cell [Int J Hydrogen Energy (2010) 33:7723-7729]. Int. J. Hydrogen Energy 37, 728 (2012).

56. Kargi, F. \& Eker, S. High power generation with simultaneous COD removal using a circulating column microbial fuel cell. J. Chem. Technol. Biotechnol. 84, 961-965 (2009).

57. Zhu, X. \& Logan, B. E. Copper anode corrosion affects power generation in microbial fuel cells. J. Chem. Technol. Biotechnol. 89, 471-474 (2014).

58. Baudler, A., Schmidt, I., Langner, M., Greiner, A. \& Schroder, U. Does it have to be carbon? Metal anodes in microbial fuel cells and related bioelectrochemical systems. Energy Environ. Sci. 8, 2048-2055 (2015).

59. Sekar, N., Wu, C.-H., Adams, M. W. W. \& Ramasamy, R. P. Electricity generation by Pyrococcus furiosus in microbial fuel cells operated at $90^{\circ} \mathrm{C}$. Biotechnol. Bioeng. 114, 1419-1427 (2017).

60. Yilmazel, Y. D., Zhu, X., Kim, K.-Y., Holmes, D. E. \& Logan, B. E. Electrical current generation in microbial electrolysis cells by hyperthermophilic archaea Ferroglobus placidus and Geoglobus ahangari. Bioelectrochemistry 119, 142-149 (2016).

This paper demonstrates electricity production at very high temperatures by iron-reducing hyperthermophiles.

61. Chen, S. \& Smith, A. L. Methane-driven microbial fuel cells recover energy and mitigate dissolved methane emissions from anaerobic effluents. Environ. Sci. (Camb.) 4, 67-79 (2018).

62. Myung, J., Saikaly, P. E. \& Logan, B. E. A two-staged system to generate electricity in microbial fuel cells using methane. Chem. Eng. J. 352, 262-267 (2018).

This paper uses methane to produce electricity in a two-stage process.

63. McAnulty, M. J. et al. Electricity from methane by reversing methanogenesis. Nat. Commun. 8, 15419 (2017).

64. Hubenova, Y. \& Mitov, M. Extracellular electron transfer in yeast-based biofuel cells: a review. Bioelectrochemistry 106 (Pt A), 177-185 (2015).

65. Raghavulu, S. V., Goud, R. K., Sarma, P. N. \& Mohan, S. V. Saccharomyces cerevisiae as anodic biocatalyst for power generation in biofuel cell: Influence of redox condition and substrate load. Bioresour. Technol. $102,2751-2757(2011)$.

66. Hubenova, Y. \& Mitov, M. Mitochondrial origin of extracelullar transferred electrons in yeast-based biofuel cells. Bioelectrochemistry 106 (Pt A), $232-239$ (2015). 
67. Hubenova, Y. V. et al. Improvement of yeast-biofuel cell output by electrode modifications. Ind. Engin. Chem. Res. 50, 557-564 (2011).

68. Sayed, E. T., Tsujiguchi, T. \& Nakagawa, N. Catalytic activity of baker's yeast in a mediatorless microbial fuel cell. Bioelectrochemistry 86, 97-101 (2012).

69. Wu, S. et al. Extracellular electron transfer mediated by flavins in gram-positive Bacillus sp. WS-XY1 and yeast Pichia stipitis. Electrochim. Acta 146, 564-567 (2014).

70. Dexter, S. C. \& Gao, G. Y. Effect of seawater biofilms on corrosion potential and oxygen reduction of stainless steel. Corros. Sci. 44, 717-723 (1988).

71. Hasvold, $\varnothing$. et al. Sea-water battery for subsea control systems. J. Power Sources 65, 253-261 (1997).

This paper provides evidence that bacteria on cathodes can improve oxygen reduction by the electrode.

72. Gregory, K. B., Bond, D. R. \& Lovley, D. R. Graphite electrodes as electron donors for anaerobic repiration. Environ. Microbiol. 6, 596-604 (2004).

73. Clauwaert, P. et al. Biological denitrification in microbial fuel cells. Environ. Sci. Technol. 41, 3354-3360 (2007).

This paper demonstrates the complete denitrification in an MFC.

74. Puig, S. et al. Autotrophic denitrification in microbial fuel cells treating low ionic strength waters. Environ. Sci. Technol. 46, 2309-2315 (2012).

75. Jiang, X. et al. Electrochemical study of enhanced nitrate removal in wastewater treatment using biofilm electrode. Bioresour. Technol. 252, 134-142 (2018).

76. Beese-Vasbender, P. F., Nayak, S., Erbe, A., Stratmann, M. \& Mayrhofer, K. J. J. Electrochemical characterization of direct electron uptake in electrical microbially influenced corrosion of iron by the lithoautotrophic SRB Desulfopila corrodens strain IS4. Electrochim. Acta 167, 321-329 (2015).

77. Cordas, C. M., Guerra, L. T., Xavier, C. \& Moura, J. J. G. Electroactive biofilms of sulphate reducing bacteria. Electrochim. Acta 54, 29-34 (2008).

78. Aulenta, F., Catapano, L., Snip, L., Villano, M. \& Majone, M. Linking bacterial metabolism to graphite cathodes: electrochemical insights into the H2-producing capability of Desulfovibrio sp. ChemSusChem 5, 1080$1085(2012)$.

79. Rhoads, A., Beyenal, H. \& Lewandowski, Z. Microbial fuel cell using anaerobic respiration as an anodic reaction and biomineralied manganese as a cathodic reactant. Environ. Sci. Technol. 39, 4666-4671 (2005).

80. Bergel, A., Feron, D. \& Mollica, A. Catalysis of oxygen reduction in PEM fuel cell by seawater biofilm. Electrochem. Commun. 7, 900-904 (2005).

81. Erable, B. et al. Marine aerobic biofilm as biocathode catalyst. Bioelectrochemistry $78,51-56$ (2010).

82. Debuy, S., Pecastaings, S., Bergel, A. \& Erable, B. Oxygen-reducing biocathodes designed with pure cultures of microbial strains isolated from seawater biofilms. Int. Biodeterior. Biodegradation 103, 16-22 (2015).

83. Malanoski, A. P. et al. Relative abundance of 'Candidatus Tenderia electrophaga' is linked to cathodic current in an aerobic biocathode community. Microb. Biotechnol. 11, 98-111 (2018).

84. Lu, Z. et al. Behavior of metal ions in bioelectrochemical systems: a review. J. Power Sources 275, 243-260 (2015).

85. Yates, M. D., Cusick, R. D. \& Logan, B. E. Extracellular palladium nanoparticle production using Geobacter sulfurreducens. ACS Sustain. Chem. Eng. 1, 1165-1171 (2013).

86. Ishii, T., Kawaichi, S., Nakagawa, H., Hashimoto, K. \& Nakamura, R. From chemolithoautotrophs to electrolithoautotrophs: $\mathrm{CO}_{2}$ fixation by Fe(II)-oxidizing bacteria coupled with direct uptake of electrons from solid electron sources. Front. Microbiol. 6, 994 (2015).

87. Rozendal, R. A., Jeremiasse, A. W., Hamelers, H. V. M. \& Buisman, C. J. N. Hydrogen production with a microbial biocathode. Environ. Sci. Technol. 42, 629-634 (2008).

88. Geelhoed, J. S. \& Stams, A. J. M. Electricity-assisted biological hydrogen production from acetate by Geobacter sulfurreducens. Environ. Sci. Technol. 45, 815-820 (2011).

89. Bajracharya, S. et al. Biotransformation of carbon dioxide in bioelectrochemical systems: state of the art and future prospects. J. Power Sources 356, 256-273 (2017).

90. Jiang, Y. et al. Carbon dioxide and organic waste valorization by microbial electrosynthesis and electro-fermentation. Water Res. 149, 42-55 (2019).

91. Nevin, K. P., Woodard, T. L., Franks, A. E., Summers, A. M. \& Lovley, D. R. Microbial electrosynthesis: feeding microbes electricity to convert carbon dioxide and water to multicarbon extracellular organic compounds. mBio 1, e00103-10 (2010).

\section{This paper is one of the first studies showing chemical production from a biocathode.}

92. Nevin, K. P. et al. Electrosynthesis of organic compounds from carbon dioxide is catalyzed by a diversity of acetogenic microorganisms. Appl. Environ. Microbiol. 77, 2882-2886 (2011).

93. Bajracharya, S. et al. Carbon dioxide reduction by mixed and pure cultures in microbial electrosynthesis using an assembly of graphite felt and stainless steel as a cathode. Bioresour. Technol. 195, 14-24 (2015).

94. Aryal, N., Tremblay, P.-L., Lizak, D. M. \& Zhang, T. Performance of different Sporomusa species for the microbial electrosynthesis of acetate from carbon dioxide. Bioresour. Technol. 233, 184-190 (2017).

95. Zhang, T. et al. Improved cathode materials for microbial electrosynthesis. Energy Environ. Sci. 6, 217-224 (2013).

96. Gildemyn, S., Rozendal, R. A. \& Rabaey, K. A. Gibbs free energy-based assessment of microbial electrocatalysis. Trends Biotechnol. 35, 393-406 (2017).

97. Clauwaert, P. \& Verstraete, W. Methanogenesis in membraneless microbial electrolysis cells. Appl. Microbiol. Biotechnol. 82, 829-836 (2008).

98. Sato, K., Kawaguchi, H. \& Kobayashi, H. Bio-electrochemical conversion of carbon dioxide to methane in geological storage reservoirs. Energy Convers. Manag. 66, 343-350 (2013).

99. Jiang, Y. et al. Bioelectrochemical systems for simultaneously production of methane and acetate from carbon dioxide at relatively high rate. Int. J. Hydrogen Energy 38, 3497-3502 (2013).

100. Cheng, S., Xing, D., Call, D. F. \& Logan, B. E. Direct biological conversion of electrons into methane by electromethanogenesis. Environ. Sci. Technol. 43, 3953-3958 (2009).

This paper provides the first reported evidence that methanogens could be using electrons directly from the cathode to produce methane.

101. Deutzmann, J. S., Sahin, M. \& Spormann, A. M. Extracellular enzymes facilitate electron uptake in biocorrosion and bioelectrosynthesis. $m$ Bio 6, e00496-15 (2015). This paper provides clear evidence that $M$. maripaludis releases enzymes that facilitate electron transfer from the cathode.

102. Van Eerten-Jansen, M. C. A. A. et al. Microbial community analysis of a methane-producing biocathode in a bioelectrochemical system. Archaea 2013, 12 (2013).

103. Siegert, M., Yates, M. D., Spormann, A. M. \& Logan, B. E. Methanobacterium dominates biocathodic Archaeal communities in methanogenic microbial electrolysis cells. ACS Sustain. Chem. Eng. 3, 1668-1676 (2015)

104. Summers, Z Ms that Methanobacterium spp. predominate on cathodes that poorly catalyse hydrogen production, but they do not predominate on platinum

105. Rotaru, A.-E. et al. Direct interspecies electron transfer between Geobacter metallireducens and Methanosarcina barkeri. Appl. Environ. Microbiol. 80, 4599-4605 (2014).

106. Rotaru, A.-E. et al. A new model for electron flow during anaerobic digestion: direct interspecies electron transfer to Methanosaeta for the reduction of carbon dioxide to methane. Energy Environ. Sci. 7, $408-415$ (2014).

107. Kato, S., Hashimoto, K. \& Watanabe, K. Methanogenesis facilitated by electric syntrophy via (semi)conductive iron-oxide minerals. Environ. Microbiol. 14, 1646-1654 (2012).

108. Liu, F. et al. Magnetite compensates for the lack of a pilin-associated c-type cytochrome in extracellular electron exchange. Environ. Microbiol. 17, 648-655 (2015).

109. Martins, G., Salvador, A. F. Pereira, L. \& Alves, M. M. Methane production and conductive materials: a critical review. Environ. Sci. Technol. 52, 10241-10253 (2018). This is a good critical review of the complicating factors involved in understanding how conductive materials can influence methane production in bioreactors.

110. Bourdakos, N., Marsili, E. \& Mahadevan, R. A defined co-culture of Geobacter sulfurreducens and Escherichia coli in a membrane-less microbial fuel cell. Biotechnol. Bioeng. 111, 709-718 (2014).

111. Karthikeyan, R., Sathish kumar, K., Murugesan, M., Berchmans, S. \& Yegnaraman, V. Bioelectrocatalysis of Acetobacter aceti and Gluconobacter roseus for current generation. Environ. Sci. Technol. 43, 8684-8689 (2009).

112. Ren, Z., Ward, T. E. \& Regan, J. M. Electricity production from cellulose in a microbial fuel cell using a defined binary culture and an undefined mixed culture. Environ. Sci. Technol. 41, 4781-4786 (2007).

113. Venkataraman, A., Rosenbaum, M. A., Perkins, S. D., Werner, J. J. \& Angenent, L. T. Metabolite-based mutualism between Pseudomonas aeruginosa PA14 and Enterobacter aerogenes enhances current generation in bioelectrochemical systems. Energy Environ. Sci. 4, 4550-4559 (2011).

114. Malvankar, N. S. et al. Electrical conductivity in a mixed-species biofilm. Appl. Environ. Microbiol. 78, 5967-5971 (2012).

115. Lovley, D. R. Electromicrobiology. Ann. Rev. Microbiol. 66, 391-409 (2012).

116. Walker, D. J. F. et al. Electrically conductive pili from pilin genes of phylogenetically diverse microorganisms. ISME J. 12, 48 (2017).

117. Li, F. et al. Engineering Shewanella oneidensis enables xylose-fed microbial fuel cell. Biotechnol. Biofuels 10, 196 (2017).

118. Choi, D. et al. Metabolically engineered glucose-utilizing Shewanella strains under anaerobic conditions. Bioresour. Technol. 154, 59-66 (2014).

119. Flynn, J. M., Ross, D. E., Hunt, K. A., Bond, D. R. \& Gralnick, J. A. Enabling unbalanced fermentations by using engineered electrode-interfaced bacteria. $m$ Bio 1, e00190-10 (2010).

120. Johnson, E. T. et al. Enhancement of survival and electricity production in an engineered bacterium by light-driven proton pumping. Appl. Environ. Microbiol. 76, 4123-4129 (2010).

121. Leang, C., Malvankar, N. S., Franks, A. E., Nevin, K. P. \& Lovley, D. R. Engineering Geobacter sulfurreducens to produce a highly cohesive conductive matrix with enhanced capacity for current production. Energy Environ. Sci. 6, 1901-1908 (2013).

122. Kouzuma, A., Oba, H., Tajima, N., Hashimoto, K. \& Watanabe, K. Electrochemical selection and characterization of a high current-generating Shewanella oneidensis mutant with altered cell-surface morphology and biofilm-related gene expression. BMC Microbiol. 14, 190-190 (2014).

123. Liu, T. et al. Enhanced Shewanella biofilm promotes bioelectricity generation. Biotechnol. Bioeng. 112, 2051-2059 (2015).

124. Ueki, T. et al. Construction of a Geobacter strain with exceptional growth on cathodes. Front. Microbiol. 9 , 1512 (2018).

125. Yang, Y. et al. Enhancing bidirectional electron transfer of Shewanella oneidensis by a synthetic flavin pathway. ACS Synth. Biol. 4, 815-823 (2015).

126. Cao, Y., Li, X., Li, F. \& Song, H. CRISPRi-SRNA: transcriptional-translational regulation of extracellular electron transfer in Shewanella oneidensis. ACS Synth. Biol. 6, 1679-1690 (2017).

127. TerAvest, M. A., Zajdel, T. J. \& Ajo-Franklin, C. M. The mtr pathway of Shewanella oneidensis MR-1 couples substrate utilization to current production in Escherichia coli. ChemElectroChem 1, 1874-1879 (2014).

128. Feng, J. et al. Enhancing the performance of Escherichia coli-inoculated microbial fuel cells by introduction of the phenazine-1-carboxylic acid pathway. J. Biotechnol. 275, 1-6 (2018).

129. Liu, T., Yu, Y.-Y., Chen, T. \& Chen, W. N. A synthetic microbial consortium of Shewanella and Bacillus for enhanced generation of bioelectricity. Biotechnol. Bioeng. 114, 526-532 (2017).

130. Liu, Y. et al. A three-species microbial consortium for power generation. Energy Environ. Sci. 10, 1600-1609 (2017).

This paper reports on a consortium of microorganisms developed to produce current from a specific substrate.

131. Kim, T., Logan, B. E. \& Gorski, C. A. A. pH-gradient flow cell for converting waste CO2 into electricity. Environ. Sci. Technol. Lett. 4, 49-53 (2017). This paper demonstrates that only concentration differences are needed to produce current.

132. Park, D. H. \& Zeikus, J. G. Electricity generation in microbial fuel cells using neutral red as an electronophore. Appl. Environ. Microbiol. 66, 1292-1297 (2000).

133. Katz, E., Shipway, A. N. \& Willner, I. in Handbook of Fuel Cells - Fundamentals, Technology and Applications Vol. 1 (eds Vielstich, W., Gasteiger, H. A. \& Lamm, A.) 1-27 (John Wiley \& Sons, Ltd, 2003).

134. Kim, B.-H. et al. Electrochemical activity of an Fe(III)-reducing bacterium, Shewanella putrefaciens IR-1, in the presence of alternative electron acceptors. Biotechnol. Tech. 13, 475-478 (1999).

135. Kim, H.-J., Hyun, M.-S., Chang, I. S. \& Kim, B.-H. A microbial fuel cell type lactate biosensor using a metal-reducing bacterium, Shewanella putrefaciens. J. Microbiol. Biotechnol. 9, 365-367 (1999).

136. Kim, B. H., Park, D. H., Shin, P. K., Chang, I. S. \& Kim, H. J. Mediator-less biofuel cell. US Patent 5976719 (1999). This paper presents the beginning of MFCs without mediators.

137. Kim, B. H., Kim, H.-J., Hyun, M.-S. \& Park, D.-H. Direct electrode reaction of Fe(III)-reducing bacterium, Shewanella putrefaciens. J. Microbiol. Biotechnol. 9, 127-131 (1999).

137. Kim, B. H., Kim, H.-J., Hyun, M.-S. \& Park, D.-H. Direct electrode reaction of Fe(III)-reducing bacterium, Shewanella putrefaciens. J. Microbiol. Biotechnol. 9,
138. Reimers, C. E., Tender, L. M., Fertig, S. \& Wang, W. Harvesting energy from the marine sediment-water interface. Environ. Sci. Technol. 35, 192-195 (2001). This is the first demonstration of how bacteria in sediments can be used to produce electrical power.

139. Tender, L. M. et al. Harnessing microbially generated power on the seafloor. Nat. Biotechnol. 20, 821-825 (2002).

140. Bond, D. R., Holmes, D. E., Tender, L. M. \& Lovley, D. R. Electrode-reducing microorganisms that harvest energy from marine sediments. Science 295, $483-485$ (2002).

141. Liu, H., Ramnarayanan, R. \& Logan, B. E. Production of electricity during wastewater treatment using a single chamber microbial fuel cell. Environ. Sci. Technol. 38, 2281-2285 (2004). This paper introduces the concept of using MFCs for waste water treatment.

142. He, Z., Minteer, S. D. \& Angenent, L. T. Electricity generation from artificial wastewater using an upflow microbial fuel cell. Environ. Sci. Technol. 39, 5262-5267 (2005).

143. Fu, Q. et al. A thermophilic Gram-negative nitrate-reducing bacterium, Calditerrivibrio nitroreducens, exhibiting electricity generation capability. Environ. Sci. Technol. 47, 12583-12590 (2013).

144. Parameswaran, P. et al. Kinetic, electrochemical, and microscopic characterization of the thermophilic, anode-respiring bacterium Thermincola ferriacetica. Environ. Sci. Technol. 47, 4934-4940 (2013).

145. Malki, M., Lacey, A. L. D., Rodríguez, N., Amils, R. \& Fernandez, V. M. Preferential use of an anode as an electron acceptor by an acidophilic bacterium in the presence of oxygen. Appl. Environ. Microbiol. 74, $4472-$ 4476 (2008).

146. Badalamenti, J. P., Krajmalnik-Brown, R. \& Torres, C. I. Generation of high current densities by pure cultures of anode-respiring Geoalkalibacter spp. under alkaline and saline conditions in microbial electrochemical cells. mBio 4, e00144-13 (2013). 
147. Kashefi, K. et al. Geoglobus ahangari gen. nov., sp. nov., a novel hyperthermophilic archaeon capable of oxidizing organic acids and growing autotrophically on hydrogen with Fe(III) serving as the sole electron acceptor. Int. J. Syst. Evol. Microbiol. 52, 719-728 (2002).

148. Nielsen, L. P. \& Risgaard-Petersen, N. Rethinking sediment biogeochemistry after the discovery of electric currents. Ann. Rev. Mar. Sci. 7, 425-442 (2015). This is a thoughtful review of how cable bacteria could be greatly impacting the biogeochemical processes in marine sediments.

149. Trojan, D. et al. A taxonomic framework for cable bacteria and proposal of the candidate genera Electrothrix and Electronema. Syst. Appl. Microbiol. 39, 297-306 (2016).

150. Reimers, C. E., Li, C., Graw, M. F., Schrader, P. S. \& Wolf, M. The identification of cable bacteria attached to the anode of a benthic microbial fuel cell: evidence of long distance extracellular electron transport to electrodes. Front. Microbiol. 8, 2055 (2017).

151. Vilajeliu-Pons, A. et al. Microbial electricity driven anoxic ammonium removal. Water Res. 130, 168-175 (2018).

152. Di Domenico, E. G. et al. Development of electroactive and anaerobic ammonium-oxidizing (anammox) biofilms from digestate in microbial fuel cells. Biomed. Res. Int. 2015, 351014 (2015).

153. Yin, X., Qiao, S., Zhou, J. \& Quan, X. Using three-bio-electrode reactor to enhance the activity of anammox biomass. Bioresour. Technol. 196, 376-382 (2015).

154. Shaw, D. R., Ali, M., Katuri, K. P. \& Saikaly, P. E. in ISMET 6 - General Meeting of the International Society for Microbial Electrochemistry and Technology (ISMET, Lisbon 2017).

155. Ruiz-Urigüen, M., Shuai, W. \& Jaffé, P. R. Feammox Acidimicrobiaceae sp. A6, a lithoautotrophic electrode-colonizing bacterium. Appl. Environ. Microbiol. https://doi.org/10.1128/AEM.02029-18 (2018).

156. Qu, B., Fan, B., Zhu, S. \& Zheng, Y. Anaerobic ammonium oxidation with an anode as the electron acceptor. Env. Microbiol. Rep. 6, 100-105 (2014).

157. Ishii, S. i. et al. Functionally stable and phylogenetically diverse microbial enrichments from microbial fuel cells during wastewater treatment. PLOS ONE 7, e30495 (2012).

158. Finster, K., Bak, F. \& Pfennig, N. Desulfuromonas acetexigens sp. nov., a dissimilatory sulfur-reducing eubacterium from anoxic freshwater sediments. Arch. Microbiol. 161, 328-332 (1994).

159. Kumar, A. et al. The ins and outs of microorganism-electrode electron transfer reactions. Nat. Rev. Chem. 1, 0024 (2017).

160. Katuri, K. P., Albertsen, M. \& Saikaly, P. E. Draft genome sequence of Desulfuromonas acetexigens strain 2873, a novel anode-respiring bacterium. Genome Announc. 5, e01522-01516 (2017).

161. Lovley, D. R. Live wires: direct extracellular electron exchange for bioenergy and the bioremediation of energy-related contamination. Energy Environ. Sci. 4, 4896-4906 (2011).

162. Li, Z., Jinlian, M., Zhen, Y., Yueqiang, W. \& Jia, T. Magnetite accelerates syntrophic acetate oxidation in methanogenic systems with high ammonia concentrations. Microb. Biotechnol. 11, 710-720 (2018).

163. Liu, F. et al. Promoting direct interspecies electron transfer with activated carbon. Energy Environ. Sci. 5, 8982-8989 (2012).

\section{Acknowledgements}

The authors acknowledge funding by the US Department of Energy (DOE) Energy Efficiency and Renewable Energy (EERE) Fuel Cell Technologies Office through a contract from the National Renewable Energy Laborator (NREL), Project \#21263, and by the Environmental Security Technology Certification Program via cooperative research agreement W9132T-16-2-0014 through the US Army Engineer Research and Development Center.

\section{Author contributions}

All authors researched data, wrote the article and reviewed and edited the manuscript before submission. B.E.L. and R.R. prepared drafts for figures 1 and 3-5, and P.E.S. and A.R. prepared Figure 2 .

\section{Competing interests}

The authors declare no competing interests.

\section{Publisher's note}

Springer Nature remains neutral with regard to jurisdictional claims in published maps and institutional affiliations.

\section{Supplementary information}

Supplementary information is available for this paper at https://doi.org/XXXXXXXX

Box $1 \mid$ The three periods of microbial fuel cell development

Michael Potter is often credited with the first studies of generation of an electrical current by several microorganisms', including by what are now named Escherichia coli and Saccharomyces cerevisiae. Subsequently, these microorganisms were found to have very poor abilities to transfer electrons to a carbon electrode and for a long time were considered by most researchers not to be exoelectrogenic ${ }^{18}$. It was possible that chemicals in the medium, such as those in yeast extract including certain $\mathrm{B}$ vitamins and flavins, provided sufficient mediators (that is, electron shuttles) to produce current in Potter's experiments. More recently, relatively high power densities have been reported for these two microorganisms but always with yeast extract in experiments with $S$. cerevisiae. Many studies have reported very little current generation using pure cultures of $E$. coli, although other laboratories found high current generation. It is also possible that the electrical current in Potter's studies was derived from the electrochemical potential produced by these microorganisms under highly reducing anaerobic conditions relative to the counter electrode. Concentration differences in carbon dioxide alone, for example, can generate low current in an electrochemical cell under abiotic conditions ${ }^{3,131}$.

The second era in microbial fuel cell (MFC) development was based on the use of exogenous mediators, but most chemicals were toxic and expensive, and thus, they offered no practical applications ${ }^{139,139}$. The third, modern era is characterized by MFCs that directly generate current without the need for exogenous mediators. In 1999, Kim and colleagues showed direct current generation (no mediators were added to the fuel cell) from pure cultures of the iron-reducing microorganism Sherwanella putrefaciens to develop biosensors ${ }^{134-137}$. Rapid advances subsequently showed current generation from anaerobic sediments to power marine sensors ${ }^{188,139}$, high current densities in mixed cultures with acetate and glucose ${ }^{44,140}$ and waste water treatment in different types of electrochemical devices ${ }^{141,142}$. Chemicals in nature undergo natural cycles of oxidation and reduction, and thus it was not surprising that experiments demonstrating oxidation of organic compounds and transfer of electrons to the anode were soon followed by discoveries that microorganisms could also accept electrons from the cathode and reduce chemicals. The first microorganism that was shown to accept electrons from an electrode was Geobacter metallireducens, which reduced nitrate to nitrite, although it could not grow using only electrons from the cathode ${ }^{72}$. Since then, many microorganisms have been shown to either donate or accept electrons from an electrode.

\section{Box $2 \mid$ Novel exoelectrogens}

In extreme environments other electroactive microorganisms not belonging to the Geobacteraceae family can predominate. Furthermore, novel exoelectrogens emerged, for example, with unique electron transport systems such as cable bacteria and exoelectrogenic ammonia-oxidizing bacteria that accomplish complete nitrogen removal.

\section{Electroactive extremophiles}

Microorganisms that can transfer electrons to a surface or another microorganism appear not to be limited to mesophilic temperatures or typical ranges of salinity and $\mathrm{pH}$. Several pure cultures have produced current at thermophilic temperatures (optimum $>45{ }^{\circ} \mathrm{C}$ ), for example, the bacteria Calditerrivibrio nitroreducens $s^{143}\left(55^{\circ} \mathrm{C}\right.$ ) and Thermincola ferriacetic $a^{144}\left(60^{\circ} \mathrm{C}\right)$. Exoelectrogenic activity has also be found for hyperthermophilic archaea (optimum $\left.>80^{\circ} \mathrm{C}\right)$, such as Pyrococcus furiosu $5^{59}$, Ferroglobus placidus and Geoglobus ahangari $i^{60}$. The mechanisms that these microorganisms use for exocellular electron transfer are not well studied, but these microorganisms have a large number of cytochromes and can reduce solid metal oxides.

Exoelectrogenic microorganisms have been found in environments with extreme $\mathrm{pH}$ variations; for example, Acidiphilum sp. strain 3.2 Sup 5 , isolated from the acidic Rio Tinto river, produced $3 \mathrm{~A} \mathrm{~m}^{-2}$ at the highly acidic $\mathrm{pH}$ of 2.5 (REF. ${ }^{145}$ ). Bacteria have also been isolated that can generate current under highly alkaline conditions $(\mathrm{pH}=9.3)^{146}$ and highly saline conditions (for example, G. ahangari, up to $3.8 \% \mathrm{NaCl}$ ) ${ }^{147}$. Thus, there are no intrinsic barriers to current generation at extreme conditions of temperature, $\mathrm{pH}$ and salinity. The use of extreme conditions, such as high temperatures, can have certain advantages such as faster growth rates or reduced chances of contamination by other microorganisms.

\section{Cable bacteria}

Cable bacteria, of the family Desulfobulbaceae, grow as electrically conductive multicellular filaments (cables) that can reach to $>1 \mathrm{~cm}^{\text {in length }}{ }^{148}$, enabling longrange electron transport. They have been assigned to the candidate genera Candidatus Electrothrix (freshwater sediments) and Candidatus Electronema (marine sediments) and grow at oxic-anoxic interfaces ${ }^{149}$. Cells in the anoxic depths of the sediment oxidize sulfides, with electrons travelling along the conductive cables to cells that extend into the oxic sediment-water interface and reduce oxygen or nitrate. It has recently been suggested that they can use a positively poised solid anode as an electron acceptor owing to the attachment of cable bacteria to anode fibres in a benthic microbial fuel cell (MFC) ${ }^{150}$.

\section{Ammonia-oxidizing exoelectrogens}

The finding that bacteria can fully oxidize ammonium to nitrogen gas, with the anode serving as an electron acceptor, is an exciting development. Electroactive bacteria of the genus Nitrosomonas were recently shown to perform anoxic autotrophic ammonium oxidation in dual chamber microbial electrolysis cells (MECs), with nitrogen removal rates of $35 \mathrm{~g} \mathrm{~m}^{-3}$ day $^{-1}\left(\right.$ REF. $\left.^{151}\right)$, which is comparable to conventional nitrification and denitrification processes $\left(21-58 \mathrm{~g} \mathrm{~m}^{-3}-\mathrm{d}^{-1}\right)$. The electrochemical activity of anaerobic ammonium-oxidizing (anammox) bacteria is not well investigated, although anammox communities related to Candidatus Brocadia spp. have been shown to be enriched in anode compartments ${ }^{21,152}$. Enriched cultures of the strain KSU-1 had different total nitrogen removal rates in response to different electrode potentials ${ }^{153}$. More recently, electrochemical activity has been confirmed in highly enriched cultures (>99\%) of the anammox bacteria Candidatus Brocadia 
sinica and Candidatus Scalindua spp. ${ }^{154}$. The ability of microorganisms such as Acidimicrobiaceae sp. A6 to oxidize ammonia and reduce iron has been termed feam$\operatorname{mox}^{155}$. Similarly, 'electroanammox' involves anoxic ammonium oxidation coupled to current generation in single-chamber MECs with no accumulation of intermediates such as nitrate, nitrite and nitrous oxide ${ }^{156}$.

\section{Other predominant exoelectrogens}

Other novel exoelectrogens that can arise in different settings such as engineered bioreactors. For example, in single-chamber, air-cathode MFCs operated for 1 year fed domestic waste water, the microbial community fluctuated, with early stages dominated by members of the genus Geobacter, but in later stages, close relatives of Desulfuromonas acetexigens were predominant, suggesting some role of this bacterium in electricity generation ${ }^{157}$. D. acetexigens strain 2873 was first isolated in 1994 from digester sludge of a sewage treatment plant ${ }^{158,159}$, but it was recently shown to produce high peak current densities $\left(9 \mathrm{~A} \mathrm{~m}^{-2}\right)$ in $\mathrm{MECs}$ fed with acetate ${ }^{160}$. This bacterium is promising for its application in microbial electrochemical technologies because it contains genes coding for outer membrane cytochromes that are known to have a key role in current generation in both G. sulfurreducens (OmcE, OmcS and OmcZ) and Sherwanella oneidensis (OmcA and MtrA). In long-terms studies of MFCs fed different types of waste water, other exoelectrogens might become predominant over time on the basis of a mix of unique characteristics in addition to those needed to produce current in these bioelectrochemical systems.

Fig. 1 Components of microbial fuel cells and other bioelectrochemical systems. Microbial fuel cells and other types of microbial electrochemical technologies contain microorganisms on the anode, cathode or both electrodes. Single-chamber systems do not contain a separator, whereas two-chamber systems contain a separator to better isolate the microorganisms or chemicals within only one of the two chambers. The separator can be made out of cloth, sizeselective membranes, ion exchange membranes or stacks of membranes (to produce power, for example, from salinity gradients). Exoelectrogenic microorganisms from all three domains of life can produce current on the anode, whereas only bacteria and archaea have been found to function as electrotrophs on the cathode. The electrodes can be treated with catalysts or binders to enhance electron transfer or interactions of microorganisms with the electrodes. Mediators can be present that shuttle electrons, but only mediators produced by the microorganisms are usually of interest so that no additional chemicals need to be added to these systems.

Fig. 2 | Diversity of exoelectrogenic and electrotrophic microorganisms. The figure shows a molecular phylogenetic analysis of $16 \mathrm{~S}$ (and $18 \mathrm{~S}$ in the case of eukaryotes) rRNA gene sequences by the maximum likelihood method for selected exoelectrogenic (part a) and electrotrophic (part b) communities (see Supplementary Box 1 for details about the used method). The outer circle classifies the species on the basis of kingdom, whereas the inner circles show the phylum-level classification for groups of two or more species. The percentage of trees $(\geq 70 \%)$ in which the associated taxa clustered together is shown next to the branch nodes on the basis of 1,000 tree iterations.

Fig. 3 Current production by exoelectrogenic microorganisms. The figure shows exemplary power densities for pure (bacteria in blue, eukaryotes in purple and archaea in green) and mixed cultures (grey) of microorganisms on the anode. Asterisks indicate that yeast extract or tryptone was used in tests. Mixed culture tests indicate the cathode type (2CA stands for a two-chamber cathode with dissolved oxygen; 1CA stands for a single-chamber, air cathode). For some microorganisms, more than one power density is shown to demonstrate the wide range of reported power densities. See Supplementary Box 2 for individual studies and references that the values are based on.

Fig. 4 | Current consumption by electrotrophic microorganisms. The figures shows current densities (bars) and applied potentials (diamonds) of pure cultures on the cathode in microbial electrosynthesis (blue) that produce organic chemicals such as acetate or ethanol and in microbial electrolysis cells (green) that primarily produce methane. The red asterisk indicates the presence of yeast extract in the medium. See Supplementary Box 3 for individual studies and references that the values are based on.

Fig. 5 | Direct interspecies electron transfer between microorganisms. Different mechanisms support direct interspecies electron transfer between microorganisms. a | Microorganisms, for example, Geobacter spp., can transfer electrons through conductive pili (black) that contain cytochromes (red circles) or by direct contact ${ }^{104,161}$. b $\mid$ Small conductive particles such as magnetite (blue circles) can also facilitate electron transfer, probably in a similar way to cytochromes on the conductive pili; it is not clear whether chains of magnetite particles can facilitate electron transfer in the absence of the pili, ${ }^{9,162}$. $\mathbf{c} \mid$ Conductive particles larger than the cells, such as activated carbon (large grey sphere), might also facilitate electron transfer between microorganisms that are not in direct contact with each other but contact the particles through outer membrane cytochromes or conductive pili9,163.

\section{Glossary}

Bioelectrochemical systems

Devices that contain microorganisms that donate to or accept electrons from an electrode.

Microbial electrochemical technologies

(METs). Bioelectrochemical systems that are used for a specific purpose, for example, microbial fuel cells used to produce electricity.

\section{Catholyte}

An electrolyte that surrounds the cathode when a bioelectrochemical system is divided into two chambers; if there is only one chamber, the cathode is exposed to the anolyte.

Exoelectrogenic

The ability of microorganisms to transfer electrons outside the cell.

Electrotrophic

The ability of microorganisms to accept electrons into the cell from external sources.

Single-chamber

A single-chamber microbial fuel cell (MFC) is an MFC with an air cathode that is exposed to air on one side and water on the other side. By contrast, two-chamber systems are reactors with a membrane that separates the anode and cathode chambers.

Anolyte

The electrolyte that surrounds the anode in a bioelectrochemical system. In one-chamber systems, the cathode is exposed to the same electrolyte.

Biocathodes

Cathodes that transfer electrons to microorganisms on the electrode surface.

ToC blurb

Electroactive microorganisms can transfer electrons to or take them up from electrodes, and they are used in applications such as microbial fuel cells. In this Review, Logan and colleagues discuss the diversity of exoelectrogenic and electrotrophic microorganisms and their functions. 